\title{
O USO DO COMPUTADOR NA EDUCAÇÃO FINANCEIRA: UM RELATO DA EXPERIÊNCIA NA EDUCAÇÃO DE JOVENS E ADULTOS
}

\author{
COMPUTER USE IN FINANCIAL EDUCATION: AN ACCOUNT OF \\ EXPERIENCE IN EDUCATION OF YOUTH AND ADULTS
}

\author{
Érika Capelato ${ }^{1}$ \\ Ueslei Viana Batista ${ }^{2}$
}

\begin{abstract}
Resumo: Este trabalho é resultado de um projeto universitário desenvolvido por meio de oficinas de educação financeira junto aos alunos do oitavo e nono ano do Ensino Fundamental da modalidade Educação de Jovens e Adultos de uma escola pública no município de Araraquara. Os objetivos do projeto foram proporcionar aos alunos discussões de temáticas que contribuíssem para aprimorar suas habilidades e competências em situações financeiras e, ainda, incluir neste contexto de ensino-aprendizagem um outro recurso, o computador. As oficinas foram desenvolvidas usando duas abordagens; uma sistêmica, com apresentação dos conteúdos; e outra, prática, com o uso do computador, especificamente de planilhas do Excel. Os resultados apontam que o computador, principalmente o software trabalhado, possibilitou aos estudantes construir e explorar os conceitos financeiros abordados nas oficinas mostrando-se, assim, uma metodologia integradora no processo de ensino-aprendizagem para a educação financeira como parte da educação matemática.
\end{abstract}

Palavras-chave: Educação de Jovens e Adultos; Ensino Fundamental; Educação Financeira; Educação Matemática; Excel.

\begin{abstract}
This work is the result of a university project developed through financial education workshops with the eighth and ninth grade students of the Youth and Adult Education modality of a public school in the city of Araraquara. The objectives of the project were to provide students with discussions on topics that contributed to improve their skills and competences in financial situations and also to include in this teaching-learning context another resource, the computer. The workshops were developed using two approaches; a systemic one, with presentation of the contents; and another, practice, using the computer, specifically Excel spreadsheets. The results show that the computer, especially the software, enabled the students to construct and explore the financial concepts addressed in the workshops, thus showing an integrative methodology in the teaching-learning process for financial education as part of mathematics education.
\end{abstract}

Keywords: Youth and Adult Education; Elementary Teaching; Financial Education; Mathematics Education; Excel.

\section{Introdução}

O nível educacional de um país ou de uma sociedade diz muito sobre o seu desenvolvimento econômico e social e vice-versa. De acordo com Piketty (2014, p. 28)

\footnotetext{
${ }^{1}$ Doutora em Matemática pela Universidade Federal de São Carlos (UFSCar). Docente na Universidade Estadual Paulista "Júlio de Mesquita Filho" (UNESP), Araraquara, São Paulo, Brasil. E-mail: erika.capelato@unesp.br

${ }^{2}$ Graduando em Ciências Econômicas na Universidade Estadual Paulista "Júlio de Mesquita Filho" (UNESP), Araraquara, São Paulo, Brasil. E-mail: viana.ueslei@gmail.com
} 
DOI: http://dx.doi.org/10.33238/ReBECEM.2019.v.3.n.2.22620

"o processo de difusão de conhecimentos e competências é o principal instrumento para aumentar a produtividade e ao mesmo tempo diminuir a desigualdade, tanto dentro de um país quanto entre diferentes países”. Nesse sentido, tanto países desenvolvidos como em desenvolvimento consideram a promoção da educação financeira uma política educacional necessária.

No caso do Brasil, podemos dizer que a trajetória da educação financeira se iniciou no ano de 2010 a partir do Decreto número 7.397, de 22 de dezembro de 2010, com a instituição da Estratégia Nacional de Educação Financeira (BRASIL, 2010). Nos anos que seguiram diversas ações começaram a ser dissiminadas; por exemplo, o Programa de Educação Financeira nas Escolas (para alunos do Ensino Fundamental e Médio) e o Programa de Educação Financeira para Adultos (mulheres do programa Bolsa-Família e aposentados com renda até dois salários mínimos). Atualmente, temos um mapeamento coordenado pela Associação de Educação Financeira do Brasil ${ }^{3}$ - AEF-Brasil, que aponta os números de iniciativas de educação financeira realizadas nas diversas regiões do Brasil nos últimos anos. De acordo com esse mapeamento, em 2009 o país identificou 64 iniciativas, em 2013 registrou 803 ações e, em 2018, o número observado foi 1300 iniciativas em todo país.

É oportuno mencionarmos que a conjuntura econômica brasileira, desde o ano da instituição da Estratégia Nacional de Educação Financeira até este momento, foi bastante heterogênea. Segundo dados de IBGE (2018), a taxa de variação do consumo das famílias (onde estão incluídas as instituições sem fins lucrativos), que em 2010 era de 6,2\%, passa para 3,5\% em 2012 e chega a 2,3\% em 2014. Já no ano de 2016, esta taxa assume o valor negativo -3,8\% e consegue uma tênue recuperação alcançando o valor de 1,4\% em 2017. Observar a taxa de variação do consumo das famílias é indispensável para análise da qualidade de vida da população e estudos sobre a pobreza.

Diante deste cenário brasileiro surgem os desafios para promover educação e alfabetização financeira. No que se refere a esses conceitos, a Organização para Cooperação e Desenvolvimento Econômico - OCDE - conceitua a educação financeira (financial education) como o processo no qual o indivíduo melhora sua compreensão sobre produtos, conceitos e riscos financeiros de maneira que, com as informações e instruções, possam desenvolver habilidades e confiança para se tornar mais consciente dos riscos financeiros e oportunidades e então, fazer escolhas bem informadas, saber onde

${ }^{3}$ http://www.vidaedinheiro.gov.br/2-mapeamento/. 


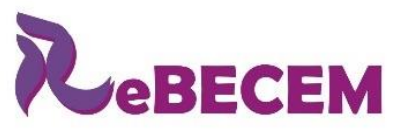

DOI: http://dx.doi.org/10.33238/ReBECEM.2019.v.3.n.2.22620
Revista Brasileira de Educação em

Ciências e Educação Matemática

procurar ajuda e adotar outras ações efetivas para melhorar seu bem estar (OECD, 2005). E define a alfabetização financeira (financial literacy) como uma combinação de consciência financeira, conhecimento, habilidades, atitudes e comportamentos necessários para tomar decisões financeiras sólidas e, finalmente, alcançar o bem-estar financeiro individual (OCDE, 2012; ATKINSON; MESSY, 2012).

Com base nessas definições, acreditamos que incluir a educação financeira como tema transversal, junto a outros temas igualmente importantes, nos conteúdos curriculares da Base Nacional Comum Curricular (BRASIL, 2018) será oportuno para ampliar no país a educação e a alfabetização financeira, reconhecida segundo Vieira, Moreira e Potrich (2019) como uma competência crítica no século 21.

Quando olhamos para a educação e alfabetização financeira no sistema escolar vemos que os conteúdos das propostas didáticas podem ser transversais, mas a educação financeira, como parte da educação matemática e matemática financeira, é nosso foco neste trabalho. Uma contextualização histórica e contemporânea da matemática financeira pode ser encontrada em Grando e Schneider (2010). Em seu artigo, os autores descrevem elementos históricos e contemporâneos que possibilita conhecer a origem da matemática financeira e como ela está ligada com os elementos que compõem o sistema financeiro, como os bancos, a moeda, os juros, entre outras coisas.

Reconhecemos que é de prima importância para os estudantes que haja na sala de aula uma aprendizagem significativa, ou seja, quando o novo conceito adquire significados para o aprendiz através de uma espécie de ancoragem em aspectos relevantes da estrutura cognitiva preexistente do indivíduo (MOREIRA, 1998). O termo ancoragem, segundo o autor, não é estático e é usado no primeiro momento para determinar que há uma interação entre o novo conhecimento e o já existente.

Assim, na elaboração e na execução de práticas pedagógicas, três pressupostos básicos da teoria da aprendizagem significativa abordada por Ausubel et al., (1980, 2013 apud TASCHETTO; KREY; BARCELLOS, 2015, p.824) são sugeridos: (i) o desenvolvimento de um material potencialmente significativo; (ii) a consideração durante as atividades da estrutura cognitiva preexistente no aluno e (iii) o estímulo da predisposição do aluno em querer aprender.

Dentre as metodologias existentes, o uso do computador pode cumprir os objetivos apontados nos três pressupostos acima. Quando olhamos o seu uso no ensino de matemática e educação financeira, vislumbramos que as planilhas eletrônicas do 


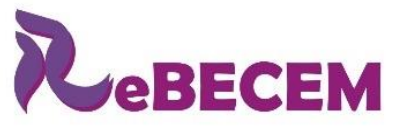

DOI: http://dx.doi.org/10.33238/ReBECEM.2019.v.3.n.2.22620
Revista Brasileira de Educação em

Ciências e Educação Matemática

Microsoft Excel, por serem de fácil acesso, podem ser um recurso didático integrador no processo de ensino-aprendizagem.

$\mathrm{Na}$ literatura podemos encontrar alguns autores que trabalharam com planilhas eletrônicas do Excel no ensino de educação financeira. Por exemplo, Almeida (2011), Coser Filho (2008) e Junior (2010) trazem propostas de atividades para o terceiro ano do Ensino Médio utilizando o Excel no ensino-aprendizagem da matemática em finanças. Em Feijó (2007) o autor investiga as diferenças existentes entre o uso das planilhas eletrônicas do Excel e da calculadora nas abordagens dos conceitos de Matemática Financeira na educação superior.

Assim, com o objetivo de contribuir com as discussões da literatura e ampliar a prática da educação e alfabetização financeira na sala de aula de matemática, este trabalho busca relatar a experiência de quatro oficinas realizadas utilizando o Microsoft Excel para os alunos do período noturno do oitavo e nono ano do Ensino Fundamental da modalidade Educação de Jovens e Adultos (EJA) de uma escola pública da cidade de Araraquara, interior de São Paulo.

A construção deste texto e sua apresentação foram estruturadas da seguinte forma: além desta introdução, apresentamos outras três seções; na primeira seção, descrevemos cada uma das oficinas; na segunda, apresentamos as percepções dos alunos, da escola e as nossas, fazendo uma análise dos resultados obtidos; finalmente, na última seção, apresentamos as considerações finais.

\section{Propostas de oficinas}

As oficinas propostas aos estudantes do oitavo e nono anos do Ensino Fundamental da modalidade EJA tiveram as seguintes temáticas: planilha eletrônica orçamentária (oficina 1); os efeitos das taxas de câmbio, inflação e Selic no dia a dia (oficina 2); juros simples e juros compostos (oficina 3) e a presença da água nos produtos que consumimos (oficina 4 ).

Cada uma destas oficinas teve duração de 50 (cinquenta) minutos e foram realizadas no período noturno, em horário e calendário estabelecidos pela coordenação da escola. Para cada uma elaboramos um problema que era apresentado para iniciarmos com os estudantes um diálogo sobre o tema. Na sequência, fazíamos uma abordagem sistêmica, tanto dos conteúdos necessários para o entendimento dos conceitos, quanto dos conceitos matemáticos utilizados na resolução do problema apresentado. E, finalmente, 
DOI: http://dx.doi.org/10.33238/ReBECEM.2019.v.3.n.2.22620

os estudantes passavam a construir e explorar estes conceitos utilizando a planilha eletrônica do Microsoft Excel, conforme descreveremos na sequência desta seção. Todas as oficinas ocorreram no laboratório de informática da escola que possuía 12 (doze) computadores. Assim, os alunos participantes foram organizados em duplas para as atividades no computador e cada oficina foi conduzida pelo bolsista do projeto e mais um colaborador.

Antes de iniciarmos a sequência das oficinas, aplicamos aos estudantes da EJA que delas participariam um questionário, o qual será apresentado e discutido na próxima seção deste texto. Os objetivos desse questionário vislumbravam conhecer o perfil dos estudantes que participariam das oficinas, no que se refere às suas percepções sobre educação financeira e o uso do computador, de modo a obter um parâmetro para fazermos a avaliação final das atividades. Os resultados desse questionário preliminar nos possibilitaram conhecer as expectativas e necessidades daquele grupo de estudantes e, com isso, nos preparar adequadamente para as oficinas.

\subsection{Oficina 1 - Planilha eletrônica orçamentária}

Os objetivos consistiram em mostrar a importância de elaborar uma planilha orçamentária como instrumento que identifica as receitas fixas e variáveis, assim como gastos fixos e variáveis, além da possibilidade que ela traz de, ao categorizarmos os setores onde há gastos mensais individuais (ou familiares), planejar o orçamento mensal levando em conta as receitas disponíveis.

Além disso, os estudantes da EJA, ao elaborarem sua planilha orçamentária, precisam ser conduzidos a observarem que ela não serve apenas como técnica para anotar os seus gastos (ou de suas famílias), mas deve colaborar na formação de um pensamento reflexivo e crítico que o ajude a construir novos conhecimentos em educação financeira.

Iniciamos esta temática dialogando com os estudantes da EJA sobre o seguinte problema, o qual foi escrito na lousa: como os recursos digitais, especificamente o computador, pode contribuir para que você encontre o percentual do seu salário que tem sido gasto com transporte, habitação, alimentação e gastos supérfluos?

Este problema favoreceu a apresentação de conceitos como receita fixa e variável, custos fixos e variáveis, além de explorarmos os conceitos de proporção e a representação das razões em gráficos setoriais. Em seguida, apresentamos o Excel como uma proposta 


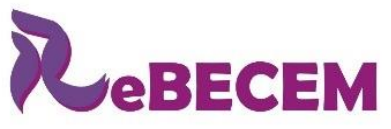

DOI: http://dx.doi.org/10.33238/ReBECEM.2019.v.3.n.2.22620

\section{Revista Brasileira de Educação em \\ Ciências e Educação Matemática}

para montar uma planilha orçamentária a partir de uma planilha do Excel, a qual já havíamos previamente preparado, veja Figura 1.

Figura 1: Atividade da primeira oficina trabalhada na sala de informática

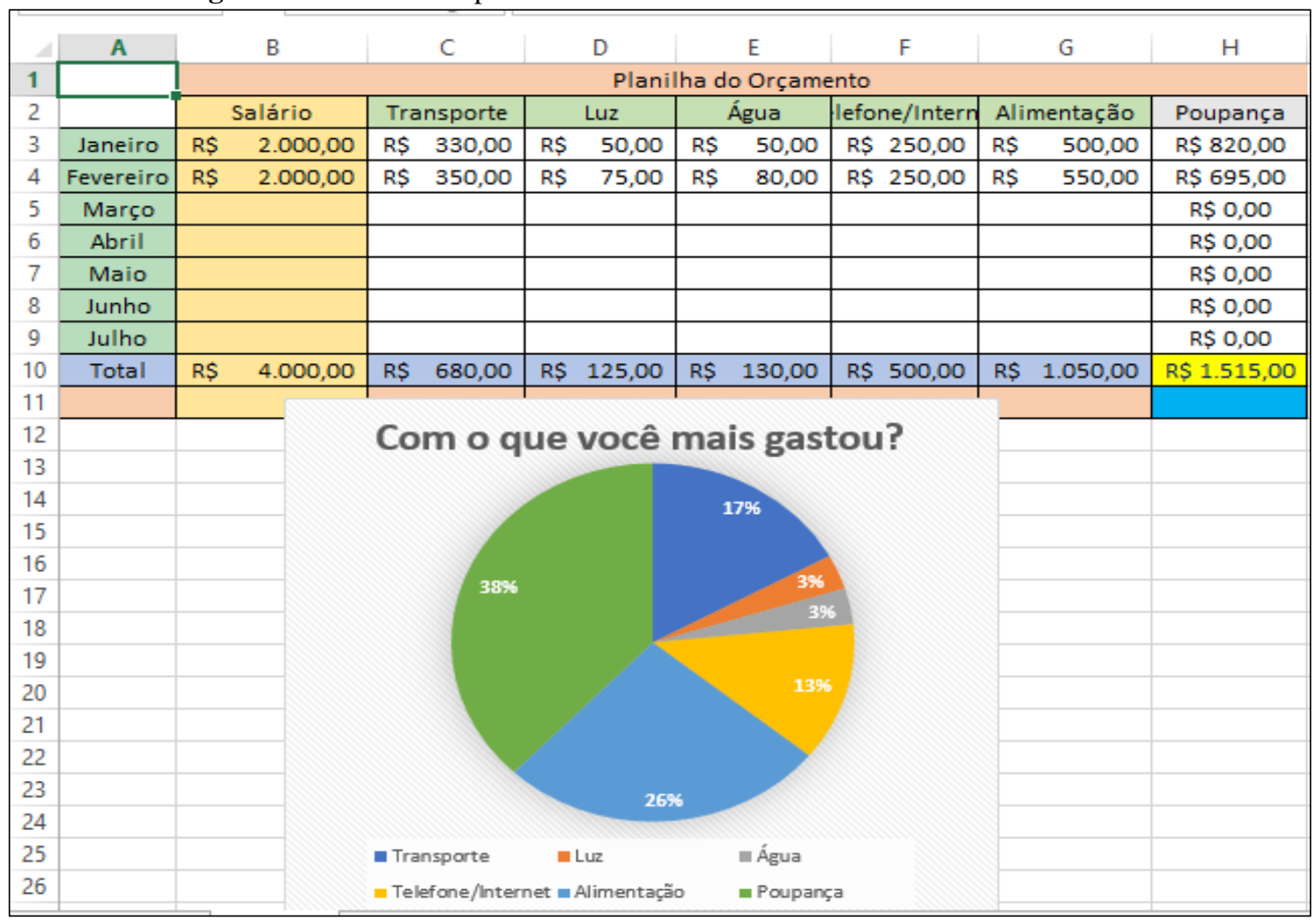

Fonte: Elaboração dos autores

$\mathrm{Na}$ planilha identificamos alguns meses do ano, o salário (receita fixa) e as categorias de custos variáveis tais como transporte, luz, água, alimentação e poupança. Com o recurso "tabelas dinâmicas", os cálculos e o gráfico eram apresentados assim que os estudantes inseriam os valores em cada categoria. O recurso é bastante flexível e permite que as modificações feitas sejam aplicadas e exibidas instantaneamente, o que foi bastante interessante já que a atividade podia ser refeita rapidamente e permitia aos alunos observarem as variações das proporções em cada categoria do gráfico.

\subsection{Oficina 2 - Os efeitos das taxas de câmbio, inflação e Selic no dia a dia}

Os objetivos desta oficina consistiram em proporcionar ao aluno a discussão e o conhecimento de três taxas que afetam o nosso dia a dia por meio dos preços e do sistema bancário: as taxas de inflação e de câmbio e a taxa Selic. Iniciamos essa temática dialogando com os estudantes da EJA sobre o seguinte problema, o qual foi escrito na lousa: que relação há entre o câmbio e a inflação? Como o câmbio e a inflação afetam 
DOI: http://dx.doi.org/10.33238/ReBECEM.2019.v.3.n.2.22620

os preços? Que relação há entre a taxa SELIC, presente no sistema bancário, e a inflação?

Auxiliado pelo bolsista, condutor da oficina, o estudante devia observar dois pontos para responder às perguntas iniciais: (i) muitos produtores brasileiros usam insumos importados e, dependendo do preço do câmbio, os preços destes insumos aumentam, gerando um custo mais alto de produção, o que leva o produtor a repassar estes custos para o consumidor, o que por sua vez eleva o preço do produto, o que gera inflação; (ii) a inflação é responsável pelo reajuste de preços no Brasil; (iii) a taxa de juros bancária Selic (Sistema Especial de Liquidação e de Custódia) é usada pelo governo para controlar a inflação, ou seja, com taxas altas as empresas e/ou consumidores que tomaram empréstimos deverão pagar mais ao banco e, com isso, há uma tendência das empresas e dos consumidores consumirem menos, o que diminui a inflação.

Após esses conceitos terem sido apresentados, os estudantes passaram a analisar uma planilha do Excel, composta com dados do Banco Central ${ }^{4}$, que elaboráramos previamente. Nela constava o valor, em reais, correspondente a um dólar (câmbio), os valores da taxa Selic e os valores da taxa de inflação para um período. Veja Figura 2.

Na primeira atividade, o aluno devia preencher a tabela referente à conversão de dólares para reais usando a taxa de câmbio expressa na planilha. Após os estudantes compreenderem que a multiplicação era a operação matemática que deviam realizar, mostramos como esta era realizada utilizando o Excel. Ou seja, utilizando as células, conforme a Figura 2, em $C 13$ e em $C 14$ deveríamos fazer as operações $=A 13 * B 13$ e $=A 14 * B 14$, respectivamente. As demais células da tabela desta planilha deveriam ser preenchidas de modo análogo. Após fazerem os cálculos, os estudantes foram incentivados a explorar a tabela modificando o valor de 500 dólares e observando a conversão do câmbio.

${ }^{4}$ https://www.bcb.gov.br/. 


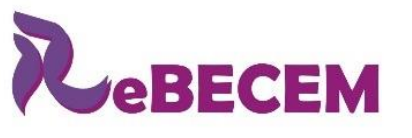

DOI: http://dx.doi.org/10.33238/ReBECEM.2019.v.3.n.2.22620
Revista Brasileira de Educação em

Ciências e Educação Matemática

ISSN 2594-9179

Figura 2: Atividade da segunda oficina trabalhada na sala de informática

\begin{tabular}{|c|c|c|c|c|c|c|c|}
\hline$\Delta$ & A & B & C & D & $\mathrm{E}$ & $\mathrm{F}$ & G \\
\hline 1 & Período & Câmbio (em reais) & Inflação (IPCA em \%) & Selic (em \%) & aluguel & IPCA $\quad-1$ & Valor ajustado \\
\hline 2 & $\mathrm{dez} / 10$ & 1,67 & 5,91 & 10,75 & 800 & 5,91 & 847,28 \\
\hline 3 & dez/11 & 1,88 & 6,5 & 11 & 800 & 6,5 & 852 \\
\hline 4 & dez/12 & 2,04 & 5,84 & 7,25 & 800 & 5,84 & \\
\hline 5 & dez/13 & 2,34 & 5,91 & 10 & 800 & 5,91 & \\
\hline 6 & dez/14 & 2,66 & 6,41 & 11,75 & 800 & 6,41 & \\
\hline 7 & dez/15 & 3,9 & 10,67 & 14,25 & 800 & 10,67 & \\
\hline 8 & dez/16 & 3,26 & 6,29 & 13,75 & 800 & 6,29 & \\
\hline 9 & dez/17 & 3,31 & 2,94 & 7 & 800 & 2,94 & \\
\hline 10 & dez/18 & 3,48 & 2,21 & 6,5 & 800 & 2,21 & \\
\hline \multicolumn{8}{|l|}{11} \\
\hline 12 & valor (em dólares) $\mathbf{v}$ & câmbio & valor em reais & & valor do empréstimo $>$ & Selic $>1$ & Valor da dívida (juros após 1 mês) \\
\hline 13 & 500 & 1,67 & 835 & & 1500 & 10,75 & 1661,25 \\
\hline 14 & 500 & 1,88 & 940 & & 1500 & 11 & 1665 \\
\hline 15 & 500 & 2,04 & & & 1500 & 7,25 & \\
\hline 16 & 500 & 2,34 & & & 1500 & 10 & \\
\hline 17 & 500 & 2,66 & & & 1500 & 11,75 & \\
\hline 18 & 500 & 3,9 & & & 1500 & 14,25 & \\
\hline 19 & 500 & 3,36 & & & 1500 & 13,75 & \\
\hline 20 & 500 & 3,31 & & & 1500 & 7 & \\
\hline 21 & 500 & 3,48 & A & 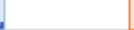 & 1500 & 6,5 & \\
\hline
\end{tabular}

Fonte: Elaboração dos autores

$\mathrm{Na}$ segunda atividade, os estudantes deveriam preencher a tabela referente ao valor da dívida após um mês aplicando a taxa de juros que constava na planilha. Para isso, mostramos inicialmente aos alunos como resolver problemas matemáticos que abordam o cálculo de porcentagens com acréscimo simples. Em seguida, mostramos como realizar este cálculo usando o Excel. As operações sugeridas, utilizando as células conforme a Figura 2, foram, nas células $G 13$ e em $G 14,=E 13+E 13 * F 13 / 100$ e $=E 14+E 14 * F 14 / 100$, respectivamente. As demais células da tabela desta planilha foram preenchidas com raciocício análogo. Após fazerem os cálculos, os estudantes foram incentivados a explorar a tabela modificando o valor do empréstimo de $\mathrm{R} \$ 1.500,00$ e observando o valor da dívida após um mês.

$\mathrm{Na}$ terceira atividade, os estudantes deveriam preencher a tabela referente ao valor do reajuste do aluguel usando o valor da inflação que constava na planilha. Novamente, mostramos que este era um problema matemático que abordava cálculo de porcentagem com acréscimo simples. Em seguida, mostramos que no Excel a operação era análoga à realizada na segunda atividade. Após fazerem os cálculos, os estudantes foram incentivados a explorar a tabela modificando o valor do aluguel de $\mathrm{R} \$ 800,00$ e observando o seu valor ajustado pela inflação.

Para finalizar esta atividade, os estudantes da EJA, auxiliados pelo bolsista e pelo colaborador que conduziam a oficina, deveriam concluir que estas taxas modificam o valor do dinheiro com o tempo e que isto pode implicar na diminuição de seu poder de compra. 
DOI: http://dx.doi.org/10.33238/ReBECEM.2019.v.3.n.2.22620

\subsection{Oficina 3 - Juros simples e composto}

O objetivo desta oficina foi abordar a existência da taxa de juros e sua incidência em diversos produtos financeiros; por exemplo, no pagamento de boletos atrasados e na correção de valores monetários aplicados na poupança. Além disso, esta oficina procurou apresentar a diferença entre juros simples e composto, tanto na execução dos cálculos como na observação dos resultados finais. Iniciamos esta temática dialogando com os estudantes da EJA sobre os seguintes problemas, que foram escritos na lousa:

1. Suponha que você esqueceu em uma gaveta um boleto de $R \$ 100,00$ referente a uma compra feita no cartão de crédito. Suponha ainda que a taxa de juros do crédito do cartão é de $10 \%$ ao mês. Após um ano você vai organizar a gaveta e encontra o boleto. Qual será o valor da dívida a ser paga se os juros forem calculados usando a capitalização simples? E se for usada a capitalização composta?

2. Uma aplicação de $R \$ 2.000,00$ foi feita a uma taxa de juros de $10 \%$ ao mês. Verifique o saldo obtido após 1 ano, entre os juros simples e os juros compostos. Esta atividade favoreceu a exploração de problemas matemáticos que envolvem porcentagens, com a ideia de aplicação de percentuais sucessivos. Assim, num primeiro momento, os estudantes acessaram uma planilha do Excel que havíamos preparado previamente para o Problema 1 descrito acima. A planilha continha duas tabelas, uma referente ao cálculo dos juros simples e outra referente ao cálculo dos juros compostos, conforme a Figura 3. 
DOI: http://dx.doi.org/10.33238/ReBECEM.2019.v.3.n.2.22620

Figura 3: Atividade da terceira oficina trabalhada na sala de informática

\begin{tabular}{|c|c|c|c|c|c|c|c|}
\hline \multicolumn{2}{|c|}{ A1 } & \multicolumn{2}{|c|}{$\times \vee f_{x}$} & \multirow[b]{2}{*}{$\mathrm{D}$} & \multirow[b]{2}{*}{$\mathrm{E}$} & \multirow[b]{2}{*}{$\mathrm{F}$} & \multirow[b]{2}{*}{ G } \\
\hline 4 & A & B & C & & & & \\
\hline 1 & & juros simples & & & & juros composto & \\
\hline \multicolumn{8}{|l|}{2} \\
\hline 3 & Mês & $10 \%$ de 100 & \multicolumn{2}{|l|}{ rendimento } & Mês & $10 \%$ do mês anterior & rendimento \\
\hline 4 & 1 & & & & 1 & & \\
\hline 5 & 2 & & & & 2 & & \\
\hline 6 & 3 & & & & 3 & & \\
\hline 7 & 4 & & & & 4 & & \\
\hline 8 & 5 & & & & 5 & & \\
\hline 9 & 6 & & & & 6 & & \\
\hline 10 & 7 & & & & 7 & & \\
\hline 11 & 8 & & & & 8 & & \\
\hline 12 & 9 & & & & 9 & & \\
\hline 13 & 10 & & & & 10 & & \\
\hline 14 & 11 & & & & 11 & & \\
\hline 15 & 12 & & & & 12 & & \\
\hline
\end{tabular}

Fonte: Elaboração dos autores

Na Atividade, o aluno devia preencher, usando os comandos do Excel, as tabelas referentes ao cálculo dos juros e ao valor da dívida. Primeiramente, observamos aos estudantes que, nos juros simples, o valor dos juros não aumentaria com o tempo, ou seja, do primeiro mês ao décimo segundo mês faríamos, em cada célula do Excel, a conta = $100 * 10 / 100$.

Após realizarem esse cálculo, ainda na tabela referente aos juros simples, eles preencheram a coluna referente à dívida. Observamos que, neste processo, somaríamos sempre 10 (dez) ao valor da dívida referente ao mês anterior. Ou seja, de acordo com a planilha da Figura 3, nas células $C 4, C 5$ e $C 6$ teríamos, por exemplo, $=100+\mathrm{B} 4,=C 4+B 5$ $\mathrm{e}=C 5+B 6$, respectivamente

Ainda que os valores favorecessem cálculos mentais, incentivamos a utilização da planilha eletrônica para que os valores dos juros simples pudessem ser comparados com os dos juros compostos. A Figura 4 mostra a tabela da planilha dos juros simples preenchida.

Em seguida os estudantes deveriam preencher a tabela dos juros compostos que estava na planilha. Primeiramente, observamos que nos juros compostos o valor dos juros aumenta com o tempo, pois os juros são calculados usando a dívida do mês anterior, ou seja, com percentuais sucessivos. 
DOI: http://dx.doi.org/10.33238/ReBECEM.2019.v.3.n.2.22620

Após esta observação sistêmica, os estudantes realizaram os cálculos na planilha do Excel. Nas células, conforme a Figura 4, o cálculo deveria ser realizado da seguinte forma: a célula $F 4$ teria o comando $=100 * 10 / 100$ e, em seguida, a célula $G 4$ era preenchida com o comando $=100+F 4$. Já a célula $F 5$ era preenchida com o comando $=G 4 * 10 / 100$ e a célula $G 5$ com o comando $=G 4+F 5$ e assim, sucessivamente, até completar todas as linhas da tabela que constavam na planilha, conforme Figura 4. Os estudantes foram auxiliados pelo bolsista e pelo colaborador que conduziam a oficina.

Figura 4: Atividade da terceira oficina trabalhada na sala de informática

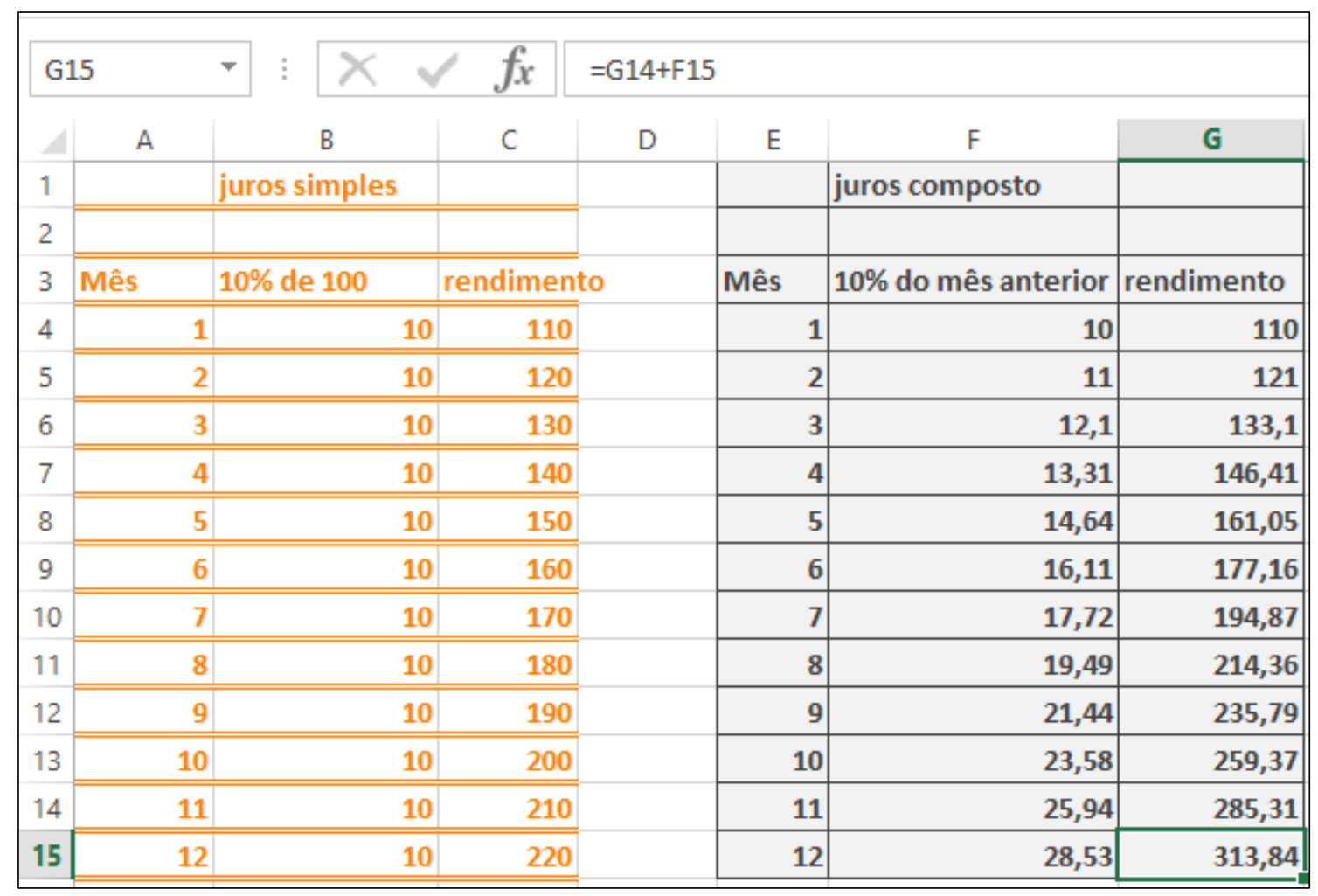

Fonte: Elaboração dos autores

Em seguida, os estudantes trabalharam de forma semelhante em uma planilha do Excel elaborada para resolver o segundo problema desta oficina. A Figura 5 mostra o resultado final da planilha desenvolvida para o segundo problema. 
DOI: http://dx.doi.org/10.33238/ReBECEM.2019.v.3.n.2.22620

Figura 5: Atividade da terceira oficina trabalhada na sala de informática

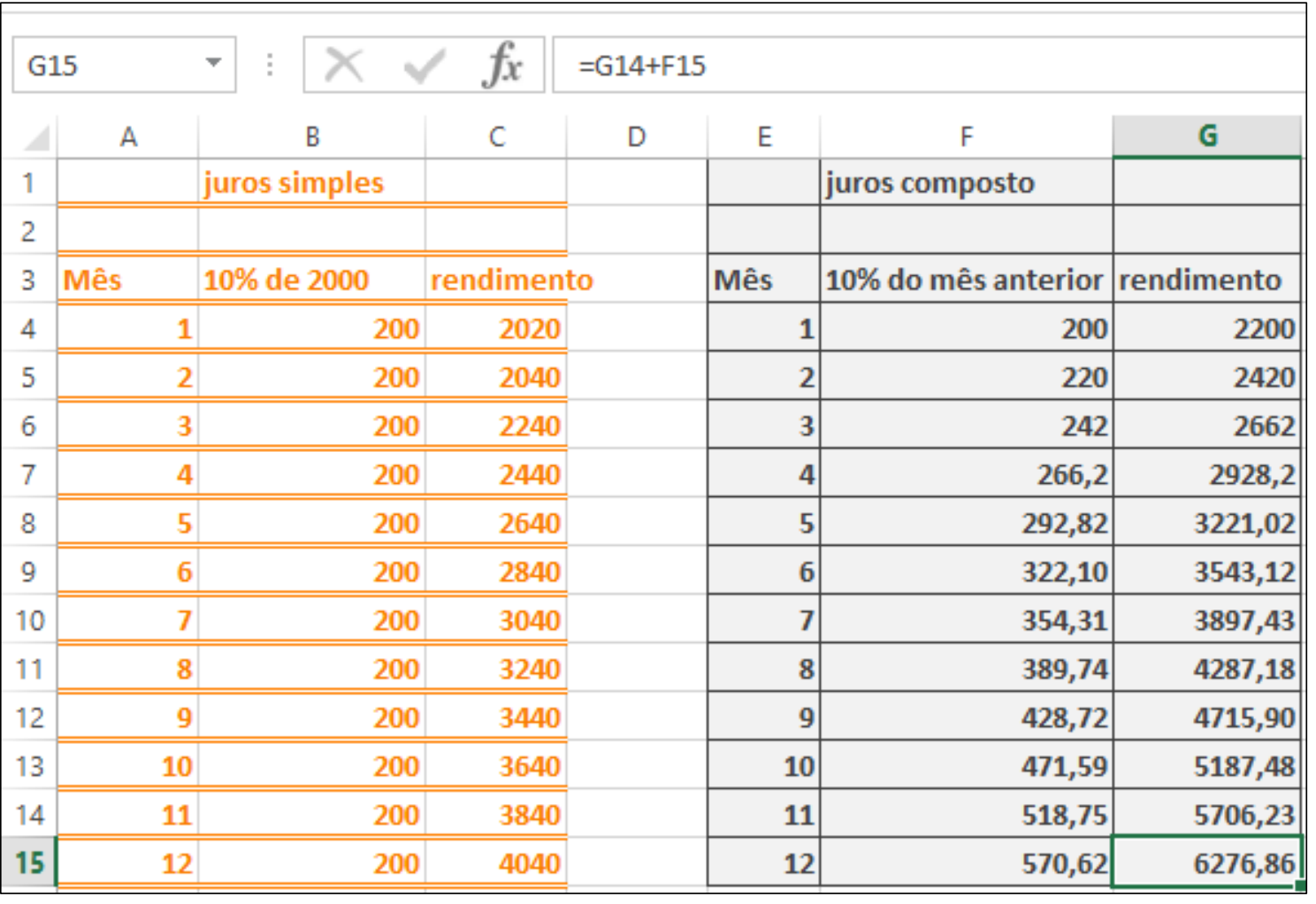

Fonte: Elaboração dos autores

Para finalizar esta atividade, o estudante deveria observar as tabelas geradas pelos cálculos dos juros simples e compostos e perceber as seguintes diferenças entre elas: nos juros simples, o valor dos juros não se altera com o tempo; já nos juros compostos, este valor se modifica a cada mês. Isto pode ser observado na maneira de fazer os cálculos e nos valores encontrados nas tabelas. Além disso, no primeiro problema, o valor final da dívida após doze meses é maior no cálculo dos juros compostos; assim como no segundo problema, o valor do rendimento final também é maior no cálculo dos juros compostos. Finalizamos esta oficina esclarecendo que os juros que incidem em diversos produtos financeiros são os compostos.

\subsection{Oficina 4 - A presença da água nos produtos que consumimos}

O objetivo desta oficina foi mostrar aos estudantes a quantidade de água que está presente em toda cadeia de produção dos bens que consumimos e, a partir desta constatação, dialogar sobre a importância de um consumo consciente que vise gerar menos impactos ambientais, principalmente em relação à escassez deste recurso.

Nesta atividade, também estávamos interessados no ensino do tratamento da informação na sala de aula, ou seja, no ensino de interpretação e construção de gráficos e 
DOI: http://dx.doi.org/10.33238/ReBECEM.2019.v.3.n.2.22620

tabelas. Segundo De Lemos (2006) a importância da compreensão e do ensino, desde cedo, desse sistema de representação na escola tem sido reconhecida internacionalmente, por diversos documentos relativos ao currículo de Matemática.

Iniciamos esta temática dialogando com os estudantes da EJA sobre o seguinte problema, que foi escrito na lousa: Água Invisível, você sabe o que é? Você já parou para pensar sobre quantos litros de água são utilizados para produzir alguns alimentos da cesta básica como o arroz, a batata e a carne bovina? Ou ainda, quantos litros de água são gastos na cadeia de produção de produtos como uma calça jeans e um smartphone?

Para esta atividade, elaboramos previamente uma planilha do Excel utilizando dados de Akatu (2010) e Hoekstra e Chapagain (2007), conforme apresentamos na Figura 6. O objetivo era analisar a planilha e utilizar o Excel para fazer gráficos como forma de apresentação destes dados.

Figura 6: Atividade da terceira oficina trabalhada na sala de informática

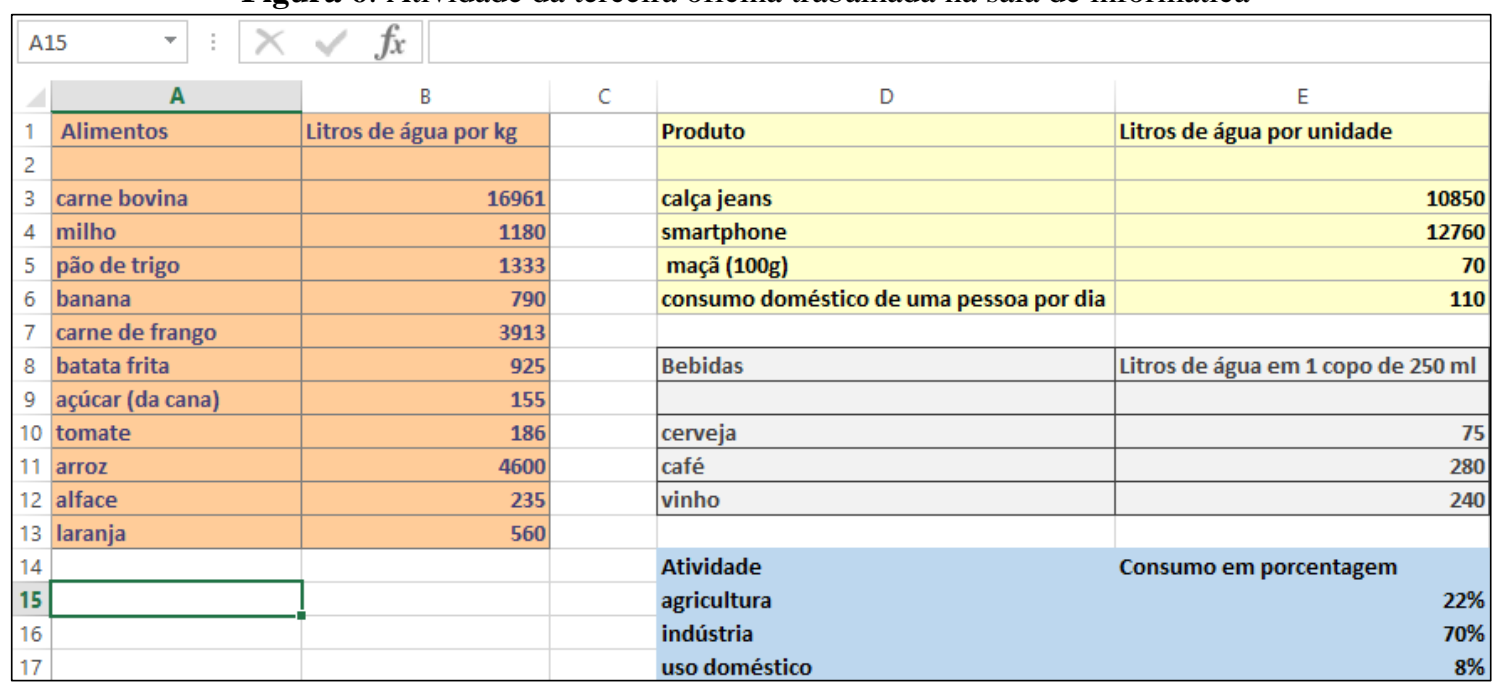

Fonte: Elaboração dos autores

Nesta oficina, pudemos explorar os gráficos de barra e de setores do Excel e discutir, entre outras coisas, dois pontos: o primeiro refere-se à utilização dos gráficos e das tabelas pelos meios de comunicação; o segundo, sobre o papel que o consumidor pode ter quando faz uma reflexão crítica sobre o consumo, ou seja, uma reflexão onde estão presentes os 5 R's - reduzir, repensar, reaproveitar, reciclar e recusar consumir produtos que gerem impactos socioambientais significativos. 
DOI: http://dx.doi.org/10.33238/ReBECEM.2019.v.3.n.2.22620

\section{Percepções sobre a experiência}

Antes de iniciarmos as oficinas elaboramos um questionário para conhecer o perfil dos estudantes que participariam das oficinas no que se tangia às suas percepções sobre educação financeira e o uso do computador, especificamente do software Excel. O questionário continha 6 (seis) perguntas de múltipla escolha e o estudante deveria assinalar uma única resposta em cada pergunta. Ao todo, responderam este questionário e participaram das atividades 45 (quarenta e cinco) estudantes do EJA que cursavam ou o oitavo ano, ou o nono ano do Ensino Fundamental. Por meio desse questionário, pudemos analisar que a idade média entre esses estudantes era de 35 anos. As perguntas e o percentual de respostas deste questionário estão na Tabela 1.

Tabela 1: Questionário inicial

\begin{tabular}{llc}
\hline \multicolumn{1}{c}{ Perguntas } & \multicolumn{1}{c}{ Alternativas } & Percentual \\
\hline 1- Você possui algum controle & ( ) Sim, anoto todos os meus gastos & $28,4 \%$ \\
de seus gastos? & ( ) Sim, mas só de cabeça & $31 \%$ \\
& ( ) Não & $20,3 \%$ \\
& ( ) Não, mas gostari & $20,3 \%$ \\
\hline 2- Em relação ao computador: & ( ) Uso todos os dias para trabalhar & $8,4 \%$ \\
& ( ) Uso todos os dias para redes & $14,9 \%$ \\
& sociais ou assistir vídeo & \\
& ( ) Uso alguns dias da semana & $27,7 \%$ \\
& ( ) Uso raramente & $27,7 \%$ \\
\hline 3- O quão importante você acha & ( ) Não uso & $21,3 \%$ \\
que é o conhecimento de & ( ) Não sei & $22,5 \%$ \\
informática para se organizar & ( ) Pode ajudar em alguns casos & $1,4 \%$ \\
financeiramente? & ( ) Muito importante & $19,7 \%$ \\
\hline 4- Você reconhece o computador & ( ) Sim & $56,3 \%$ \\
como um ambiente seguro para & ( ) Não & $39,4 \%$ \\
realizar transações bancárias e & & $60,6 \%$ \\
fazer compras? & & \\
\hline 5- Já teve algum contato com o & ( ) Nunca & $74 \%$ \\
software Excel anteriormente? & ( ) Poucas vezes & $26 \%$ \\
\hline 6- O que você acha do Excel? & ( ) Sempre & $0 \%$ \\
\hline & ( ) Não sei usar & $75 \%$ \\
\hline
\end{tabular}

Fonte: Elaboração dos autores com base nas respostas dos estudantes

Uma análise da Tabela 1 mostra, a partir da primeira pergunta, que 40,6\% dos estudantes que responderam este questionário não fazem nenhum tipo de controle dos seus gastos. Na pergunta 2, pudemos perceber que apenas 8,4\% destes estudantes usavam o computador todos os dias para trabalhar. Na pergunta 3, observamos que 56,3\% destes estudantes acham que o conhecimento em informática é muito importante para se organizar financeiramente. Na pergunta 4 observamos que $60,6 \%$ destes estudantes não 
DOI: http://dx.doi.org/10.33238/ReBECEM.2019.v.3.n.2.22620

acham o computador um ambiente seguro para compras e transações financeiras. Nas perguntas 5 e 6, referentes ao Excel, observamos que 74\% nunca tiveram contato com o software e $75 \%$ não sabem utilizá-lo.

Diante da análise das respostas obtidas na Tabela 1, pudemos perceber que o uso do Excel nas oficinas seria um desafio, o que se tornou nossa principal motivação nessa proposta de ensino e aprendizagem.

Ao finalizarmos as quatro oficinas, aplicamos um questionário final com o objetivo de conhecermos o que os estudantes acharam da experiência de discutir e estudar tópicos de educação financeira com o uso do computador, especificamente com o Excel. O questionário continha 5 (cinco) questões de múltipla escolha na qual os estudantes deveriam assinalar somente uma das alternativas. As perguntas e o percentual das respostas do questionário final se encontram na Tabela 2.

Tabela 2: Questionário final

\begin{tabular}{llc}
\hline \multicolumn{1}{c}{ Perguntas } & \multicolumn{1}{c}{ Alternativas } & Percentual \\
\hline 1- O quão importante você acha & ( ) Não sei & $4,3 \%$ \\
que é o conhecimento de & ( ) Pouco importante & $0 \%$ \\
informática para se organizar & ( ) Pode ajudar em alguns casos & $26,1 \%$ \\
financeiramente? & ( ) Muito importante & $69,6 \%$ \\
\hline 2- Você reconhece o computador & ( ) Sim & $46,7 \%$ \\
como um ambiente seguro para & ( ) Não & $53,3 \%$ \\
realizar transações bancárias e & & \\
fazer compras? & & \\
\hline 3- O que você achou do Excel? & ( ) Não sei usar & $21,7 \%$ \\
& ( ) Acho difícil & $10,9 \%$ \\
& ( ) Útil para estudar e trabalhar & $67,4 \%$ \\
\hline 4- Em relação as oficinas que & ( ) Não achei interessante & $0 \%$ \\
ocorreram com o Excel? & ( ) Elas foram interessantes & $73,9 \%$ \\
& ( ) Elas foram difíceis & $10,9 \%$ \\
\hline 5- O uso do computador para & ( ) Não quero opinar & $15,2 \%$ \\
estudar educação financeira: & ( ) Facilitou minha & $73,3 \%$ \\
& aprendizagem & $15,6 \%$ \\
& ( ) Motivou as aulas & $11,1 \%$ \\
\hline
\end{tabular}

Fonte: Elaboração dos autores com base nas respostas dos estudantes

É possível perceber que as perguntas 1 e 2 da Tabela 2, referente ao questionário final, também constavam na Tabela 1, referente ao questionário inicial. Em relação à pergunta 1 da Tabela 2, pudemos observar que, antes das oficinas, 22,5\% dos estudantes que responderam ao questionário não sabiam o quão importante era o conhecimento em informática para se organizar financeiramente; porém, após as oficinas, este percentual passa a ser 4,3\%. Em relação a pergunta 2 da Tabela 2, pudemos observar que, antes das oficinas, $60,6 \%$ dos estudantes não reconheciam o computador como um ambiente seguro 


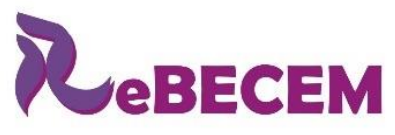

DOI: http://dx.doi.org/10.33238/ReBECEM.2019.v.3.n.2.22620
Revista Brasileira de Educação em

Ciências e Educação Matemática

para realizar transações bancárias e fazer compras; porém, após a realização das oficinas, este percentual cai para 53,3\%. Ambos os decréscimos podem estar associados a uma segurança, adquirida com as oficinas, em relação ao uso do computador, mas não é a pretensão deste trabalho investigar esta hipótese.

Ainda há uma semelhança, com possibilidade de comparação entre as perguntas 6 da Tabela 1 e a pergunta 3 da Tabela 2; antes das oficinas, 18,1\% dos estudantes achavam o Excel difícil e, após as oficinas, este percentual reduziu-se a 10,9\%.

Finalmente, analisando as perguntas 4 e 5 da Tabela 2, podemos observar que $73,9 \%$ dos estudantes acharam as oficinas com o uso do Excel interessantes e 73,3\% dos estudantes responderam que o uso do computador facilitou a aprendizagem da educação financeira.

Além das percepções dos estudantes que participaram das oficinas, as quais foram apontadas acima, podemos descrever as percepções da direção da escola que acolheu este projeto, além de nossas próprias percepções. Ainda que de forma tímida, o corpo docente da escola em que realizamos este projeto já havia utilizado o computador em algumas aulas. Assim, esta foi uma demanda inicial da coordenação desta escola, a qual avaliou positivamente os resultados da experiência para seus alunos. Eles ainda consideram importante a abordagem da educação financeira nos conteúdos curriculares e a inclusão de tecnologias no processo de aprendizagem.

Como condutores destas oficinas, percebemos que o processo de ensinoaprendizagem intermediada pelo computador provocou mudanças significativas tanto na construção didática das atividades quanto na construção do conhecimento. Por exemplo, duas perguntas balizaram nossas ações: primeiro, como propor atividades onde os estudantes conseguissem viver experiências significativas; a segunda vem de Lévy (1993) e refere-se a como utilizar o computador como processo integrador do ensinoaprendizagem e não apenas como ferramenta que facilita e automatiza os cálculos.

No que concerne à construção do conhecimento percebemos, entre outras coisas, que os estudantes encaram o "erro" de forma mais positiva quando estão no computador e sentem-se mais motivados a refazer a atividade. Além disso, observamos que o desconhecimento por parte dos estudantes do Excel não foi um fator negativo e, ao contrário, desafiador durante toda a experiência. Nas primeiras oficinas, notamos uma maior insegurança dos estudantes em relação ao computador e ao software; mas, com a sequência das oficinas, eles compreenderam gradualmente a metodologia e perceberam que podiam contar com a ajuda do professor que conduzia a atividade. 


\section{Considerações finais}

O termo educação financeira carrega consigo grande diversidade de conteúdos que podem ser inseridos como temas transversais na prática da sala de aula, desde a educação básica até o nível superior. Neste artigo, fazemos um relato da experiência prática na sala de aula de estudantes do oitavo e nono anos do Ensino Fundamental da modalidade EJA, onde desenvolvemos quatro oficinas abordando conteúdos da educação financeira como parte da educação matemática. Para isso, utilizamos o computador, especificamente a planilha eletrônica do Excel, na sequência didática que abordou os seguintes conceitos financeiros: planilha orçamentária; os efeitos das taxas de câmbio, inflação e Selic no dia a dia; juros simples e compostos e a presença da água nos produtos que consumimos.

Podemos dizer que uma limitação desta experiência seria o possível viés nas respostas dos questionários propostos, já que as expectativas dos estudantes da EJA em participar deste projeto poderiam ensejar respostas equivocadas ao questionário. No entando, a percepção da experiência como um todo sugere positivamente o uso do computador, especificamente do Excel, na abordagem da educação financeira para os estudantes da EJA. Porém, é importante mencionarmos que, para utilizar a planilha eletrônica do Excel, o professor deve ter um plano de aula razoavelmente objetivo. Além disso, é importante que os alunos percebam que a utilização destas planilhas eletrônicas ajuda a explorar alguns detalhes que, fora do ambiente da planilha, não poderiam ser explorados.

Outras práticas, que aperfeiçoem as técnicas apontadas neste relato e ampliem o uso do compulador com outros softwares que contribuam com a aprendizagem da educação financeira, podem ser desenhadas para as salas de aula da EJA. Porém, o uso destes recursos pode ser um desafio aos educadores de matemática pois, assim nos parece, pressupõe mudanças epistemológicas.

Agradecimentos: Os autores agradecem a colaboração de Vinícius Felizatti Jacinto e Willian Augusto Machado na execução deste projeto. Além disso, ao Programa Núcleos de Ensino da UNESP, pela bolsa e financiamento concedidos ao projeto. 


\section{Referências}

DOI: http://dx.doi.org/10.33238/ReBECEM.2019.v.3.n.2.22620

AKATU, Equipe. Setores industrial e agropecuário são campeões de consumo de água. Akatu: consumo consciente para um futuro sustentável. São Paulo, 2010. Disponível em: https://www.akatu.org.br/noticia/setores-industrial-e-agropecuario-sao-campeoes-no-consumode-agua. Acesso em: 26 jun. 2018.

ALMEIDA, J. X. de. Matemática nas Finanças: uma experiência com Excel. 2011. Monografia (Especialização em Matemática, Mídias Digitais e Didática) - Instituto de Matemática, Universidade Federal do Rio Grande do Sul, Porto Alegre, 2011.

ATKINSON, A.; MESSY, F. A. Measuring Financial Literacy: Results of the OECD / International Network on Financial Education (INFE) Pilot Study. OECD Working Papers on Finance, Insurance and Private Pensions, Paris, n. 15, p. 1-72, mar. 2012.

BRASIL. Casa Civil. Decreto no 7.397, de 22 de dezembro de 2010. Brasília, 2010. Disponível em: http://www.planalto.gov.br/ccivil_03/_ato2007-2010/2010/decreto/d7397.htm. Acesso em: 06 jun. 2019.

BRASIL. Ministério da Educação. Base Nacional Comum Curricular: Educação é a base. Brasília, 2018. Disponível em: http://basenacionalcomum.mec.gov.br/wpcontent/uploads/2018/04/BNCC_EnsinoMedio_embaixa_site.pdf. Acesso em: 06 jun. 2019.

COSER FILHO, M. S. Aprendizagem de Matemática Financeira no Ensino Médio: uma proposta de trabalho a partir de planilhas eletrônicas. 2008. Dissertação (Mestrado em Ensino de Matemática). Instituto de Matemática, Universidade Federal do Rio Grande do Sul, Porto Alegre, 2008.

DE LEMOS, M. P. F. O estudo do tratamento da informação nos livros didáticos das séries iniciais do ensino fundamental. Ciência \& Educação, Bauru, SP, v. 12, n. 2, p. 171-184, 2006.

FEIJÓ, A. B. O ensino de matemática financeira na graduação com a utilização da planilha e da calculadora: uma investigação comparativa. 2007. Dissertação (Mestrado em Ciências e Matemática) - Faculdade de Física, Pontifícia Universidade Católica do Rio Grande do Sul, Porto Alegre, 2007.

GRANDO, N. I.; SCHNEIDER, I. J. Matemática financeira: alguns elementos históricos e contemporâneos. Zetetike, Campinas, v. 18, n. 1, p. 43-62, 2010.

HOEKSTRA, A. Y.; CHAPAGAIN, A. K. Water footprints of nations: water use by people as a function of their consumption pattern. In: CRASWELL, E. et al. (org) Integrated assessment of water resources and global change: A North-South Analysis. Paris, França: Springer, 2007. p. $35-48$.

IBGE. Síntese de indicadores sociais: uma análise das condições de vida da população brasileira. Coordenação de População e Indicadores Sociais. Rio de Janeiro, 2018.

JUNIOR, I. M. Educação financeira: conceitos e contextos para o Ensino Médio. In: ENCONTRO NACIONAL DE EDUCAÇÃO MATEMÁTICA, 10., 2010, Salvador. Anais... Ilhéus, BA: Via Litterarum, 2010. p.1-11.

LÉVY, P. As tecnologias da inteligência: o futuro do pensamento na era da informática. $2^{\mathrm{a}}$. Edição. Rio de Janeiro: Editora 34, 1993. 
DOI: http://dx.doi.org/10.33238/ReBECEM.2019.v.3.n.2.22620

MOREIRA, M. A. Mapas conceituais e aprendizagem significativa. Cadernos de Aplicação, [S.I.], v.11, n.2, p.143-156, 1998.

ORGANISATION FOR ECONOMIC CO-OPERATION AND DEVELOPMENT - OECD. Improving Financial Literacy: Analysis of Issues and Policies. 2005, Paris, France: OECD Publishing.

ORGANISATION FOR ECONOMIC CO-OPERATION AND DEVELOPMENT -OECD. High-Level Principles on National Strategies for Financial Education. 2012, Paris, France: OECD Publishing.

PIKETTY, T. O capital no século XXI. 1. ed. Rio de Janeiro: Editora Intrínseca, 2014.

TASCHETTO, A.G; KREY, I. G; BARCELLOS, L. C. Atividades baseadas na Aprendizagem Significativa (AS): avanços na Educação de Jovens e Adultos a partir da Interdisciplinaridade como atitude do professor. Ciência e Natura, Santa Maria, v. 37, n. 3, p. 821-834, set./dez. 2015.

VIEIRA, K. M; MOREIRA, F. J; POTRICH, A. C. G. Indicador de educação financeira: proposição de um instrumento a partir da teoria da resposta ao item. Educação \& Sociedade, Campinas, SP, v. 40, p. 1-33, abr. 2019.

Recebido em: 15 de junho de 2019.

Aceito em: 03 de agosto de 2019. 